\title{
Electrolyte-free Parenteral Nutrition Emulsion
}

National Cancer Institute

\section{Source}

National Cancer Institute. Electrolyte-free Parenteral Nutrition Emulsion. NCI Thesaurus.

Code C97255.

An electrolyte-free emulsion for infusion consisting of a three chamber bag system containing glucose, amino acids and lipids that can be used to provide parenteral nutritional supplementation. The lipid emulsion portion contains soybean oil, mediumchain triglycerides, olive oil and fish oil; the amino acid solution contains alanine, arginine, glycine, histidine, leucine, isoleucine, lysine, methionine, phenylalanine, proline, serine, taurine, threonine, tryptophan, tyrosine, and valine. The electrolyte-free parenteral nutrition emulsion contains no electrolytes, trace elements and vitamins. The three separate bags containing glucose, amino acids and lipids are mixed together before infusion. 